\title{
A Formação do Leitor: Entre Imposições e Liberdades
}

\author{
The formation of the reader: between impositions and freedoms
}

\author{
Maria Ester Vieira de Sousa* \\ *Universidade Federal da Paraíba, UFPB, João Pessoa - PB, 58050000, e-mail: \\ teca.vieiradesousa@gmail.com \\ Raquel Monteiro da Silva Freitas** \\ ** Universidade Federal da Paraíba, UFPB, João Pessoa - PB, 58050000, e-mail: \\ kelzinha_cades@hotmail.com
}

\begin{abstract}
RESUMO: Neste artigo, pretendemos enfocar a temática da leitura e da formação do leitor, universo já tão saturado de discursos, priorizando a perspectiva do leitor e de suas histórias de leitura na escola e fora dela. Para dar conta desse objetivo, analisaremos relatos de leitura de alunos do curso de Letras da Universidade Federal da Paraíba. Os dados foram coletados a partir de uma produção textual, na qual os alunos deveriam fazer um relato de suas histórias de leitura, solicitado no período 2013.1 pela professora da disciplina Leitura e Produção de Texto I, oferecida no primeiro período do referido Curso. Objetivamos analisar concepções, funções e valores atribuídos à leitura subjacente aos discursos desses leitores. Como embasamento teórico-metodológico para a análise dos dados, este trabalho se pauta principalmente em autores que concebem a leitura como prática social e cultural - a exemplo de Certeau (1994), Chartier (1999a, 1999b, 2009) Abreu (1999), Autor (2009, 2011 e 2014). Nessa perspectiva, o leitor é uma figura que oscila entre aquilo que as instituições determinam e as operações efetivas de leitura que denunciam a existência de uma ação que não se recobre pela passividade. A análise demonstrou que a formação do leitor caminha entre liberdades de escolhas dos objetos da leitura e obrigações, principalmente, estabelecidas no interior da instituição escolar. Além disso, percebemos que o leitor atribui diferentes valores e funções à leitura, decorrentes, principalmente, do modo a partir do qual ele se apropria dos objetos de leitura.
\end{abstract}

PALAVRAS-CHAVE: Leitura. História de leitura. Formação do leitor.

ABSTRACT: In this article, we intend to focus on the theme of reading and the formation of reader, already so saturated universe of discourse, prioritizing the reader's perspective and their reading stories inside and outside school. To realize this goal, we will analyze reports of reading students letters course of Federal University of Paraíba. Data were collected from a textual production, in which the students should make an account of their stories reading, requested for the period 2013.1 The teacher of Reading and Textual Production I discipline, offered in the first sentence of that course. We aimed to analyze concepts, functions and values assigned to the reading underlying the speeches of these readers. As theoretical and methodological basis for the analysis of data, this work is guided mainly by authors who think of reading as a social and cultural practice - like Certeau (1994), Chartier (1999a, 1999b, 2009) Abreu (1999), Sousa (2009, 2011 and 2014). In this perspective, the reader is a figure that oscillates between what the institutions determine and actual read operations that denounce the existence of an action which 


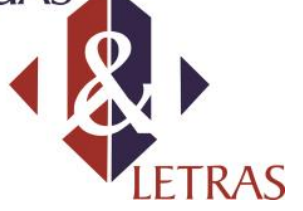

does not overlies the passivity. The analysis showed that the training of reader walks between freedom of choice of reading objects and obligations mainly established within the school institution. Also, we realize that the lector assigns different values and functions to read, due mainly to the mode from which it appropriates reading objects.

KEYWORDS: Reading. reading history. Formation of the reader.

\section{INTRODUÇÃO}

$\mathrm{Na}$ sociedade, atualmente envolvida e/ou imersa efetivamente em recursos tecnológicos e digitais, é impossível não visualizar as mudanças que estas têm revelado em relação à leitura. Os modos de ler já não são os mesmos e vêm mudando numa velocidade surpreendente. Essa proliferação e multiplicação pandêmica de informações a que se refere Fischer (2006) têm tomado conta deste século e tem adentrado às escolas, gerando necessidades de mudanças no currículo escolar, bem como, ao que parece, no modo de se trabalhar leitura na escola.

Entretanto, vale salientar que o tema da leitura, enfocando suas diferentes demandas e concepções, não é algo novo no cenário brasileiro. No século XX, conforme Sousa (2011),intensifica-se um discurso - bastante recorrente no século XIX (ABREU, 2011) - que retoma o tema da crise da leitura, acompanhado da necessidade da formulação/criação de programas de incentivo à leitura. Contudo, antes da década de 80 do século XX (SOUSA, 2011), no meio acadêmico brasileiro, são escassas as pesquisas em leitura. Ezequiel Teodoro da Silva (1983) chega mesmo a afirmar:

[...] com exceção de meia dúzia de trabalhos sérios e elucidativos, a maioria das investigações produzidas na área da leitura, nesses últimos vinte anos, poderia ir direto para a lata de lixo ou permanecer "lacrada" na estante da biblioteca (SILVA, 1983, p.78) ${ }^{1}$.

Para o autor, a década de oitenta do século XX marca "um verdadeiro renascimento dos estudos relativos aos problemas de leitura do povo brasileiro" (SILVA, 1983, p. 80). Note-se que é sob o signo dos "problemas de leitura" que as pesquisas renascem (!) ou se instauram. Assim, mesmo que o foco das pesquisas seja a crise da leitura, acaba-se falando sobre o que se lê, o quanto se lê (pouco) e o que se deveria ler. Em outras palavras, também se pode ler nessas pesquisas, discursos sobre a leitura correta e sobre os objetos dignos de serem lidos.

\footnotetext{
${ }^{1}$ Sousa (2011), ao comentar essa afirmação de Silva (1983), dentre outras considerações, chama a atenção para o fato de que seria importante questionar o porquê de essas pesquisas revelarem uma qualidade tão incipiente a ponto de serem grosseiramente chamadas de lixo.
}

Volume 18

Número 39 


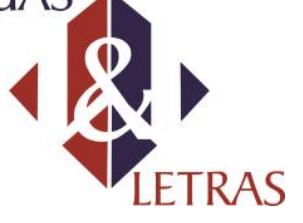

e-ISSN: $1981-4755$

DOI: $10.5935 / 1981-4755.20170008$

Neste artigo, pretendemos entrar nessa temática já tão saturada de discursos, priorizando a perspectiva do leitor e de suas histórias de leitura na escola e fora dela. Para tanto, utilizaremos, como dados de análise, 7 (sete) relatos de história de leituras de alunos recém-ingressos no curso de Letras da Universidade Federal da Paraíba ${ }^{2}$. Os dados foram coletados a partir de uma produção textual, solicitada pela professora da disciplina Leitura e Produção de Texto I, oferecida no primeiro período do referido Curso, em que os alunos falavam sobre suas histórias de leitura. Esses relatos tornamse ainda mais relevantes na medida em que revelam a relação do leitor (graduando em Letras) com a leitura no ensino fundamental e médio, ou seja, histórias (escolares) de leitura de sujeitos que terão como função formar leitores. Nesse artigo, nosso objetivo principal é, ao contemplar essas memórias que falam de leituras efetivamente realizadas por esses leitores, verificar que concepções, funções e valores atribuídos à leitura estão subjacentes a esses discursos.

\section{UM DISCURSO SOBRE A LEITURA}

É inegável, na sociedade contemporânea, o valor positivo atribuído à prática de leitura. Frases de efeito expostas nas redes sociais apresentam afirmações positivas relacionadas ao bem que a leitura pode trazer às pessoas. Esses benefícios vão desde a facilidade na escrita até o aumento do senso crítico. Além disso, rótulos sobre leitura, considerados politicamente corretos, circulam diariamente nos discursos de professores, de alunos, nas campanhas publicitárias, feiras de livros, congressos e eventos nacionais e internacionais. Antecipando os resultados de nossa análise, é o que veremos de maneira recorrente nos discursos dos sujeitos aqui analisados. Muitos, para não dizer a maioria, atribuem à leitura esses mesmos valores. Isso nos permite afirmar que a leitura é um bem cultural cujo conteúdo já está cristalizado e superestimado. .

No entanto, Abreu (1999) e Sousa (2009) ressaltam que é preciso investigar qual é o objeto da leitura. Assim, trazemos para esse contexto de discussão os questionamentos de Sousa (2009, p. 2268): “A leitura de todo e qualquer texto engrandece a alma? A leitura de todo e qualquer texto emancipa o sujeito?”. É evidente que, quando se exalta a leitura dessa maneira, não se trata de qualquer leitura, mas de certas leituras autorizadas, institucionalizadas, a partir de um cânone estabelecido

\footnotetext{
2 Os dados para esse trabalho resultaram de um recorte estabelecido em corpora de pesquisa anterior, constituído de 19 relatos de história de leitura escritos, coletados inicialmente para trabalho de dissertação de mestrado (FREITAS, 2013), defendida junto ao Programa de Pós-Graduação em Linguística da UFPB.

Volume 18
}

Número 39 


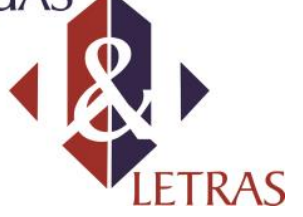

histórica e culturalmente. Ou seja, é reconhecido socialmente, hoje - e sempre foi nas mais diferentes épocas - que leitor competente, o bom leitor, é aquele que faz certas leituras e não outras. E ainda mais: é preciso ler o que é socialmente aceito, caso contrário, não será considerado nem mesmo leitor, sem nenhuma adjetivação. Abreu (1999), discorrendo sobre práticas de leitura, afirma:

\begin{abstract}
Por detrás de afirmações corriqueiras nos dias atuais, como "ler é bom" há uma seleção implícita de um conjunto de obras que tornam "bom" o ato de ler e que justificam outras tantas afirmações, também bastante comuns, como "os jovens não têm o hábito da leitura". Na verdade, lê-se muito livro de auto-ajuda, de vulgarização científica, muita ficção científica, história em quadrinho, lê-se muito sobre hobby, sobre astros da música e do cinema, muitas recolhas de piadas. Mas lê-se pouco "bons livros": pouca filosofia, pouca literatura erudita, pouca reflexão política séria. Em resumo, parece haver uma diminuição do interesse pelos livros positivamente avaliados pela escola, pela academia, pela crítica literária. [...] Novo perigo ronda o mundo da leitura, pois espera-se que esses valores fossem reverenciados e entendidos como algo de que não se poderia prescindir. (ABREU, 1999, p. 14-15)
\end{abstract}

Abreu (1999) também sinaliza que essa "ausência” da leitura considerada salutar e útil não é de hoje. Até porque o que hoje muitos consideram como leitura de boa qualidade já foi considerada o "lixo cultural" de outra época, como o romance, por exemplo, que, em séculos anteriores, era visto como uma leitura de pessoas com pouca instrução, uma leitura que pouco trazia prestígio e, por essa razão, deveria ser evitada ${ }^{3}$.

Desse modo, compreendemos que essa prática sempre existiu - a seleção de objetos da leitura - o que mudam são os objetos, as pessoas que leem e os modos como leem. Compreendemos, igualmente, que a leitura pode ser contemplada a partir de diversas óticas. Nesse artigo, contudo, escolhemos abordá-la como processo dinâmico no qual o leitor é ativo, participa da construção de sentido, a partir de diferentes táticas (CERTEAU, 1994). Enfim, a leitura, nesse sentido, é prática social, engajada no cotidiano, e não se desvincula do leitor, dos objetos dados a ler e do modo de ler. Durante muito tempo, no método escolástico, conforme apresentado por Manguel (1997), a leitura foi apresentada, por exemplo, como objeto de recitação e decodificação gráfica: "O mérito desse tipo de leitura não estava em descobrir uma significação particular do texto, mas em ser capaz de recitar e comparar as interpretações de autoridades reconhecidas e, assim, tornar-se 'um homem melhor'.” (MANGUEL, 1997,

\footnotetext{
${ }^{3}$ Para um maior aprofundamento acerca da circulação e apropriação do romance no Brasil dos séculos XVIII e XIX, ver, dentre outras fontes, Abreu (1999 e 2012) e Barbosa (2014)
}

Volume 18

Número 39 


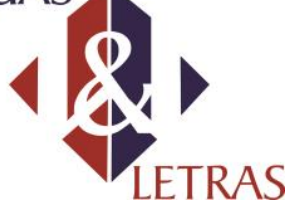

e-ISSN: $1981-4755$

DOI: $10.5935 / 1981-4755.20170008$

p.97) (grifos do autor). Hoje, há outros méritos a partir dos quais a leitura é contemplada.

Considerando os diversos aspectos sob os quais a leitura se apresenta, já na década de 80 do século XX, Orlandi (1988) trazia uma discussão que ainda se mantém atual, dado remeter para a polissemia da própria noção de leitura. Para a autora, a leitura pode ser vista como "atribuição de sentidos", em um sentido mais amplo; pode ser vista como "concepção"; como "construção de um aparato teórico"; ou, ainda, num sentido mais restrito, como decodificação, como é o caso da escola, onde a leitura é formalmente abordada enquanto conteúdo de ensino. Assumindo a perspectiva discursiva, concordamos com a autora quando afirma que a leitura "[...] não é uma questão de tudo ou nada, é uma questão de natureza, de condições de modos de relação, de trabalho, de produção de sentidos, em uma palavra: de historicidade". (ORLANDI, 1988, p. 9)

Nesse sentido, os aspectos levantados por Orlandi (1988) - a natureza da leitura, as condições e modos de relação, a produção de sentidos, a historicidade - remontam a leitura como um processo onde "sujeitos e sentidos se constituem simultaneamente" (ORLANDI, 1988, p. 10). Assim, a leitura demanda práticas que vão além do ato de decodificar, revelando diferentes processos culturais e sociais de apropriação. Para Soares (2009), ler demanda

[...] um conjunto de habilidades e comportamentos que se estendem desde simplesmente decodificar sílabas ou palavras até ler Grande Sertão Veredas de Guimarães Rosa ... uma pessoa pode ser capaz de ler um bilhete, ou uma história em quadrinhos, e não ser capaz de ler um romance, um editorial de jornal... Assim: ler é um conjunto de habilidades, comportamentos, conhecimentos que compõem um longo e complexo continuum (SOARES, 2009, p. 48).

É interessante destacar que esse conjunto de habilidades, comportamentos, conhecimentos está marcado socialmente e, segundo Foucault (2011), é controlado, organizado, incluído ou excluído, de acordo com as relações de poder. No entanto, cumpre observar que as práticas sociais da leitura podem se revelar naturalizadas ou irromper como novas, desafiadoras, avessas a classificações. Essa ideia é também corroborada por Chartier (1999a), quando, ao destacar a liberdade do leitor, afirma:

Toda história da leitura supõe, em seu princípio, esta liberdade do leitor que desloca e subverte aquilo que o livro pretende impor. Mas esta liberdade leitora não é jamais absoluta. Ela é cercada por limitações derivadas das capacidades, convenções e hábitos que 
caracterizam, em suas diferenças, as práticas de leitura. Os gestos mudam segundo os tempos e lugares, os objetos lidos e as razões de ler. Novas atitudes são inventadas, outras se extinguem. (CHARTIER 1999a, p.77)

Certeau (1994), semelhante a Foucault, analisa a leitura como uma prática imersa em uma "ordem do discurso": para ele, “[...] ler é peregrinar por um sistema imposto" (CERTEAU, 1994, p. 264). Nessa perspectiva, o sistema controla, disciplina, mas, ainda assim, é possível burlar esse sistema. O leitor, "viajante que circula em terras alheias", com suas astucias, vai construindo sentido nem sempre desejados pelos autores ou pelas instituições (a escola, a igreja, a família, etc.) que controlam os sentidos. Para Certeau, (1994, p. 267- 268). “[...] a criatividade do leitor vai crescendo à medida que vai decrescendo a instituição que a controlava". [...]

Assim, para Certeau, o leitor adquire independência conforme são transformadas as relações sociais que impõem o modo de relação com o texto. $\mathrm{O}$ autor lembra que, na Idade Média, nas leituras religiosas, o leitor não tinha autonomia, só podia receber o texto sem "refazê-lo", não podia transformá-lo, nem ser construtor de seus sentidos. E compara esse processo com o que ocorre nos dias atuais com a televisão, quando alguns analistas concebem os telespectadores como "consumidores" passivos, colocados na impossibilidade de traçar sua própria escrita na telinha onde aparece a produção do Outro - "da cultura" (CERTEAU 1994, p. 264).

Chartier (1999b, p.13), em seus estudos sobre as práticas de leituras e impressos na Europa entre os séculos XIV e XVIII, seguindo de perto as formulações de Certeau (1994), considera que “[...] a leitura é sempre uma prática encarnada em gestos, espaços e hábitos" e acrescenta que "essas determinações que governam as práticas dependem das maneiras pelas quais os textos podem ser lidos - e lidos diferentemente por leitores que não dispõem das mesmas ferramentas intelectuais, e que não mantêm uma mesma relação com o escrito." (CHARTIER, 1999b, p. 13)

Os objetivos, modos, momentos e espaços de leitura são diferentes em cada sociedade e podem variar de acordo com as comunidades de leitores que se apropriam do texto. Um texto literário pode ser lido por lazer e puro prazer, e, em outro momento, esse mesmo texto pode ser trabalhado na escola como proposta de uma determinada atividade em que necessariamente o prazer não se estabelece. Não se trata, assim, de uma mesma leitura, ou do mesmo leitor. Ainda que seja o mesmo indivíduo da leitura de lazer e da atividade, os olhos são outros, os objetivos da leitura se distanciarão, a função leitor é necessariamente outra. Assim: “[...] o essencial é compreender como os 


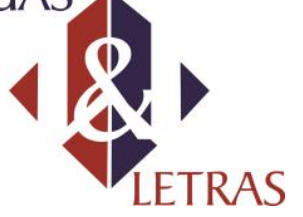

mesmos textos podem ser diversamente apreendidos, manejados e compreendidos" (CHARTIER, 1999b, p. 16), em função, dentre outros fatores, dos objetivos e dos espaços de leitura.

Os diferentes discursos sobre a leitura, aqui enunciados, não são de todo divergentes. Eles apontam diferentes pontos de vista sobre um mesmo objeto (a leitura e o leitor) que ora dialogam entre si, ora se excluem. Ao brevemente recuperar esses discursos, pretendemos demonstrar que falar sobre a história do leitor implica recorrer ao que teoricamente se diz sobre essa figura.

\section{COM A PALAVRA O LEITOR: EXPLICITAÇÃO DE PERCURSOS E PERCALÇOS}

Não podemos negar que a família teve/tem um papel bastante significativo na formação de leitores, pois é através dela que pode haver os primeiros contatos com as práticas sociais sistematizadas da leitura, mesmo não ocorrendo, em alguns casos, o processo de alfabetização como um todo. Conforme verificamos em Sousa (2008 e 2014) e Freitas (2013), agentes influenciadores como a primeira professora, os colegas e espaços como a biblioteca são responsáveis pelos encaminhamentos desses sujeitos à leitura, vista por eles como aventura, conhecimento, novos horizontes.

Sales (2009, p. 38) considera a escola, e, mais especificamente, a sala de aula como um:

[...] lugar em que o aluno tem alguém - o(a) professor(a) supostamente preparado para conduzi-lo no mundo da leitura. $\mathrm{O}$ espaço de sala de aula deve ser o lugar no qual se materializa a tarefa básica da escola: possibilitar ao aluno o acesso à leitura enquanto um ato de produção de sentidos. (SALES, 2009, p. 38)

Nesse momento, Sales (2009) refere-se a leitura, no interior da escola, em sentido, embora no decorrer de seu trabalho delimita a investigação para a leitura do texto literário. É com foco nesse espaço que apresentaremos os depoimentos a seguir, a partir dos quais os sujeitos revelam a sua relação com a leitura na escola. Vejamos os depoimentos:

$\mathrm{A} 1^{4}$ - Incentivo escolar foi à palavra chave em minha vida. Meus pais nem foram tão instruídos para me dar incentivo para a leitura,

\footnotetext{
${ }^{4}$ Os alunos serão identificados como A1, A2, A3... para facilitar a análise dos recortes estabelecidos. Os recortes citados não sofreram correções. No processo de digitação, mantivemos na íntegra o texto manuscrito dos alunos.
} 
mas sempre me deram apoio no que fosse preciso, o que eu aprendi sobre leitura a responsável foi à escola. Toda a minha vida eu estudei em escola pública, mas desde a quinta série em diante comecei a me interessar pela leitura. No começo de minha alfabetização quando aprendi a ler todo outdoor eu lia tudo que tivesse que ler eu lia. Sempre fui atenta a leitura. A princípio a escola incentivava os alunos a lerem, mas com um detalhe: quem lesse mais livros ganharia algum prêmio. Muito criança ainda, comecei a ler por interesse dos prêmios, mas o gosto pela leitura foi tão grande que já não estava mais lendo só pelos prêmios, estava lendo pelo gosto, pelo prazer. A leitura me fascinava, cada livro um mundo diferente da minha realidade. (grifos nossos)

A2 - E foi na $1^{\text {a }}$ série, agora $2^{\circ}$ ano do Ensino Fundamental I, que comecei a interagir com o mundo da leitura, porque ler é se deslocar para um estado imaginário, passa de leitor a personagem (pelo menos pra mim), mas isso só acontece quando o livro lido é de seu gosto, você tem que querer ler o livro, e não ser jogado em suas mãos. Lembro como dias atrás, a aventura que vivia ao lado de Magali e Chico Bento. Minha primeira passagem pra o mundo imaginário, meu primeiro e melhor gibi, pudera eu lê-lo novamente. Os batimentos aceleravam diante de cada aventura lida. (grifos nossos)

A3 - Aos sete anos, eu aprendera a ler. Entrei na escola um pouco tarde, aos seis anos, mas logo tomei um profundo gosto pela leitura e desde então, os livros e revistas entraram na minha vida para nunca mais saírem. Sempre lia tudo o que via pela frente, pois cada vez mais eu sentia um prazer e necessidade imensuráveis de conhecer o mundo das palavras. Li todos os clássicos rapidinho, entre eles O Pequeno Polegar, A Bela e a Fera, Rapunzel e os Três Porquinhos, amava os contos de Christian Andersen, incluindo $\mathrm{O}$ patinho Feio, O Soldadinho de Chumbo, Os Dois Nicolaus, O Rouxinol, não podendo me esquecer de A Pequena Vendedora de Fósforos e A Princesa e a Ervilha. (...) e, ao visitar uma biblioteca pela primeira vez, parecia que eu tinha ido a uma espécie de paraíso, com tudo que eu precisava para ser feliz: milhares de livros, grandes, pequenos, grossos, finos, não importava, tudo o que eu queria era mergulhar naquela imensidão de palavras e me saciar delas. Lia muito, todos os dias ia lá e pegava um. Peguei amizade com a bibliotecária, e ela se impressionava como eu gostava tanto de ler. (grifos nossos)

Nesses depoimentos, notemos que a escola cumpre a tarefa apresentada por Sales (2009). Está claramente evidenciada a influência positiva da escola: esta foi a principal responsável não só pela aquisição do código escrito (o processo de alfabetização), mas também pelo prazer, pela formação do gosto pela leitura em sentido amplo. A1, inclusive, é enfática quando diz "Incentivo escolar foi à palavra chave em minha vida". Apesar de dizer que seu interesse começou a partir da quinta série (atual sexto ano do ensino básico), ela afirma que, desde a alfabetização, o desejo pela leitura já havia florescido. À escola também foi atribuído o surgimento da paixão pela leitura: 


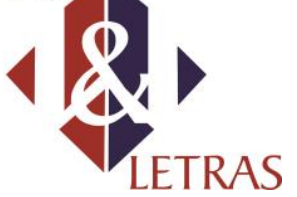

"A princípio a escola incentivava os alunos a lerem, mas com um detalhe: quem lesse mais livros ganharia algum prêmio."

É importante destacar que a escola utilizou uma estratégia de promoção da leitura, que, em geral, não é considerada como ideal, pelo fato de fazer com que o aluno leia tão somente, visando aos prêmios. Contudo, é preciso verificar que, no caso de A1, esse detalhe fez toda a diferença: o jogo de interesses funcionou muito bem, ajudando, a partir de uma prática sistemática, a construir o prazer pela leitura. Além disso, as leituras realizadas por A1 a fascinavam, pois faziam com que ela adentrasse em um mundo diferente do seu.

Nesse sentido, cabe-nos ressaltar que o discurso de A1, como também os de A2 e A3, diverge de algumas teorias que afirmam que o leitor geralmente sente prazer por uma leitura que representa seu mundo real, conforme, por exemplo, Lajolo (2006). Ou seja, nos recortes mencionados, as leituras realizadas atraíram os leitores exatamente pelo efeito contrário, por representarem uma realidade bem diferente da sua, ou, de algum modo, por representar o mundo no qual gostariam de estar inseridos, o mundo ideal. O mesmo ocorre com A4 e A5, respectivamente:

A4 - Eu viajava dentro dos contos que me tiravam da realidade e me jogavam dentro de um mundo de pura magia. Tudo era fantástico que até pensei em ser escritora e comecei a redigir textos próprios até que percebi que não era tão fácil quanto eu supunha. (Grifos nossos)

A5 - (...) e no meio em que eu vivia, eu era diferente por gostar de ler e ouvir música popular brasileira meus amigos diziam que eu ia ficar doida de tanto ler, mais eu gosto de ler, ler me faz esquecer os problemas, me faz viajar em um mundo que não existe, em um mundo que eu gostaria que existisse. (grifos nossos)

O fato de essas leituras representarem outros mundos que não eram o da realidade vivida por esses sujeitos, talvez, seja o motivo de tão grande atração por esse tipo de leitura, exatamente por eles desejarem viver o (no) mundo descrito nas páginas dos livros lidos. Vejamos que A5 era considerada excêntrica e candidata a louca ("eu ia ficar louca de tanto ler") pelos colegas pelo fato de ler bastante. Mas, para essa leitora, essa era uma tática para "esquecer os problemas", "para viajar" em outro mundo.. Nesse caso, podemos dizer que, diferente do que pensavam os amigos, a leitura a salvava da loucura. A opinião dos amigos recupera tão somente outro lugar comum sobre a leitura que está longe de a fechar nas redomas de uma positividade absoluta. Como aponta 


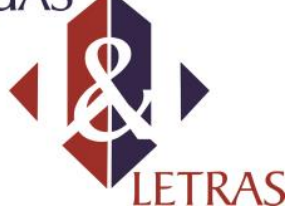

Abreu (1999), durante muito tempo, a leitura foi (e ainda hoje é) considerada maléfica e prejudicial à saúde mental e física do leitor o qual poderia ficar louco, cego ou com a coluna torta! Além de desconstruir esse discurso sobre a leitura, A5 põe em xeque outro que fala acerca dos objetos privilegiados de leitura: no seu depoimento, não importa o que se lê ou para quê se lê, simplesmente se lê. Talvez esse seja o motivo de ser considerada tão excêntrica pelos colegas.

A2 afirma que começou "a interagir com o mundo da leitura" bem cedo, na primeira série ( $2^{\circ}$ ano do ensino fundamental). O leitor, nesse caso, já se afirma recuperando um discurso sobre a leitura: a leitura é um mundo com o qual o leitor precisa interagir ${ }^{5}$. Além disso, A2 claramente explicita sua concepção de leitura e de leitor: "ler é se deslocar para um estado imaginário, passar de leitor a personagem (pelo menos pra mim)". Essa é uma leitura que referencia a prática da leitura do texto literário, tal qual comenta Barthes (1984):

Ao fechar-se para ler, ao fazer da leitura um estado absolutamente separado, clandestino, no qual o mundo inteiro é abolido, o leitor - o lente - identifica-se com dois sujeitos humanos - para dizer a verdade bem próximos um do outro - cujo estado requer igualmente uma separação violenta: o sujeito amoroso e o sujeito místico. (...) Isto confirma bem que o sujeito leitor é um sujeito inteiramente deportado sob o registro do imaginário; toda a sua economia de prazer consiste em cuidar da sua relação dual com o livro (isto é, com a Imagem), fechando-se a sós com ele, de nariz em cima dele, se ouso dizer, como a criança colada à Mãe e o Amoroso suspenso do rosto amado. (BARTHES, 1984, p.35) (grifos do autor).

O leitor identifica-se de tal forma com o objeto lido que "o mundo inteiro é abolido" e ele vive num imaginário como se estivesse vivendo a obra lida. Além disso, A2 praticamente descarta a leitura por obrigação, pois “[...] isso (o prazer) só acontece quando o livro lido é de seu gosto, você tem que querer ler o livro, e não ser jogado em suas mãos." Ou seja, esse processo de tornar-se personagem, de imersão na leitura só ocorre quando é o leitor quem escolhe o livro e não quando a escola o impõe. Essas leituras fazem o corpo falar ("os batimentos cardiacos aceleravam") e dizer o extremo prazer que elas provocam. Mas, como afirma o próprio leitor, para que isso aconteça, "você tem que querer o livro".

\footnotetext{
${ }^{5}$ Não é demais lembrar que a palavra interação tem sido recorrente em várias perspectivas teórica sobre a leitura - a exemplo das abordagens de natureza discursiva - para dar conta do movimento que envolve o leitor e texto.
}

Volume 18

Número 39 


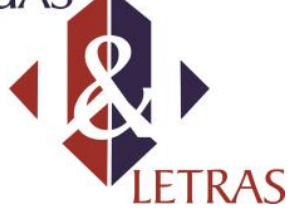

Contudo, como pondera Sousa (2008), a liberdade do leitor para escolher o que lê liga a leitura ao prazer, mas o cotidiano do sujeito leitor o "constrange", o obriga a ler o que não quer: na sociedade atual, somos constrangidos a ler sempre, e não apenas na escola. É fato que a escola é o lugar em que a leitura é sempre lembrada sob o signo da obrigação e de uma prática que, em geral, não agrada aos alunos. Conforme Sousa (2009, 2010 e 2014), o imperativo "É preciso ler!" consolida-se no interior da escola. E ler, utilizado como verbo intransitivo não apresenta objeto, o que, por sua vez, é escolhido por outrem que não o sujeito da leitura. Assim, a escola apresenta seus percalços, pois, ao mesmo tempo que motiva, estimula e cria leitores, também desestimula e desencanta muitos leitores.

Voltemos a ouvir A2, leitor apaixonado, em cujo depoimento também está presente o discurso do desencanto da leitura na escola. Vejamos:

\begin{abstract}
A2 - Ao entrar no Ensino Fundamental II, nova cidade, nova escola pública, novos professores, o que implica dizer, novo método de ensino e meu prazer por leitura assassinado, a "Tia" manda a gente tem que obedecer, contos são bons, mas eu já era "gente grande" (assim eu achava). E ler: A feiurinha, pluft, de conto em conto e outros tão sem sabor que agora me fogem da memória, fez mau a minha concepção de leitura. Mas já no fim do fundamental, ganhamos a "livre escolha", eu estava abalado com todos aqueles contos de gosto alheio, e só retornei a ter prazer (por sinal, maior que antes), no ensino médio. (grifos nossos)
\end{abstract}

Iniciado pelo prazer de ler gibis que faziam os batimentos cardíacos acelerar, esse sujeito não deseja certas leituras indicadas pela escola (“tão sem sabor"), pois já se sente um leitor adulto capaz de estabelecer suas escolhas. Observemos que A2 contesta a indicação de obras que, poderíamos dizer, hoje são consideradas um cânone da literatura infantil ${ }^{6}$. Além disso, fugir à memória, como aponta $\mathrm{A} 2$, foi um esquecimento, diríamos, programado, visto que, nesse contexto, não interessava para esse leitor relembrar as leituras de gosto alheio. Assim, nem sempre os esquecimentos que acompanham a memória são inconscientes, mas, não poucas vezes, são estratégicos, fazem parte do discurso, dizer algo de uma maneira e não de outra, lembrar isso e não aquilo. Como aponta Pêcheux (1975), esses esquecimentos são de ordem enunciativa. Essas leituras "esquecidas" são diferentes das leituras realizadas por prazer, as lembradas. Por essa razão, esse leitor afirma que essas leituras impostas fizeram mal à

\footnotetext{
${ }^{6} \mathrm{O}$ primeiro livro citado tem como autor Pedro Bandeira e foi lançado em 1986; o segundo é uma obra teatral, criada por Maria Clara Machado, em 1955.
}

Volume 18

Número 39 


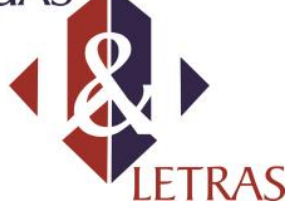

sua concepção de leitura. Concepção essa que, pelo seu discurso, é sinônimo de prazer, e fora isso, o que resta é o "assassinato" da leitura.

No entanto, é preciso ter calma e não culpar a escola por ausências de estímulos à leitura, pois, ao final do relato, esse mesmo sujeito, demonstrando que o leitor não é uno, traz outro discurso. Seu interesse pela leitura foi ressuscitado no Ensino Médio, no interior da escola, com maior intensidade:

(4)

A2 - Como se não bastasse, mais uma vez nova escola, lá ganhei bastante incentivo, mas me tornei mais exigente, isso resultou em uma diminuição de livros lidos por ano. Durante o último ano do ensino médio, li apenas 5 livros: Madame Bovary, A Conjectura de Goldbach, Sexualidade, Eu robô. Mas, o Conde de Monte Cristo foi último e o melhor. Depois dele passei a procurar 2 livros (não encontrados ainda): Medo e Psicopata. (grifos nossos)

Diferentemente de quando estava no Ensino Fundamental e a professora impunha seus gostos aos alunos, agora o leitor "ganha bastante incentivo" e se torna "mais exigente". Notemos que o verbo "ganhar" traz um outro sentido para a leitura na escola: se ganhar algo é receber um presente, a leitura na escola, como um presente, não se impunha como obrigação, ao contrário, se oferecia ao leitor. Assim, "incentivo" e "imposição" são palavras que, para A2, fizeram toda diferença, visto que "ler não suporta imperativo", já dizia Daniel Pennac (2011) no seu livro "Como um romance”. E como esse leitor já possuía certa "autonomia", passou a ler menos, pois já não é leitor de "qualquer coisa".

Como afirma Abreu (1999), os tratados setecentista, além de determinar a maneira correta de ler, pregavam que um bom leitor não deveria ler qualquer coisa, era preciso escolher bem o que leria. No caso de A2, no ensino médio, não são mais os gibis, vistos por ele como leituras mais simples, que o cativam, mas sim obras consagradas como Madame Bovary, A Conjectura de Goldbach, Conde de Monte Cristo, ou ainda, Best sellers, como, Eu robô e, Sexualidade. O amadurecimento do leitor, nas próprias palavras de A2, o torna "mais exigente", ou seja, ler muito, nessa perspectiva, não é ler quantitativamente, mas sim qualitativamente.

Vejamos agora mais exemplos dessa dualidade própria à escola: as influências positivas e negativas na vida desses sujeitos:

A6 - Ao ingressar na escola aos cinco anos não me recordo de ter ouvido, lido ou folheado um livro. Mas recordo-me de que na $3^{\text {a }}$ série 
( $4^{\circ}$ ano hoje), fui levada a ler livros paradidáticos como: O Segredo de Tonhão, que do autor não me recordo e $O$ Desafio de Manoel Bandeira. No ensino médio, não fui muito incentivada à lê (sic) pela escola. Mas sempre nas aulas vagas que tinha ia junto com alguns colegas a biblioteca no centro de João Pessoa para ler alguns livros, no entanto nunca terminava de lê-los pois o tempo era pouco e não podíamos levar os livros para casa. (grifos nossos)

Nesse depoimento, vemos o quanto o trabalho da escola desestimulou a prática da leitura. O modo como fala da leitura dos paradidáticos é sintomático: "fui levada a ler”. Não há nenhum entusiasmo, nada revela uma influência positiva. A iniciativa própria, procurar uma biblioteca fora da escola, no centro da cidade, assinala um movimento diferenciado: o leitor, mesmo não encontrando incentivo na escola, busca saída. Contudo, mais uma vez, a relação leitura/livro é interditada: "nunca terminava de lê-los pois o tempo era pouco e não podíamos levar os livros para casa."7 De qualquer modo, é preciso assinalar que o ambiente escolar favoreceu o desenvolvimento de uma prática de leitura mais do que a escola propriamente dita. Geralmente, associamos as influências advindas da escola apenas às atribuídas aos professores ou a projetos desenvolvidos no interior da escola, mas nunca ao ambiente de modo geral, como aos colegas de sala de aula. No depoimento de A6, verificamos que a inserção do sujeito no ambiente escolar amplia possibilidades de leitura, para além daquelas que a escola como instituição proporciona ${ }^{8}$.

Vejamos, ainda, o depoimento de A7:

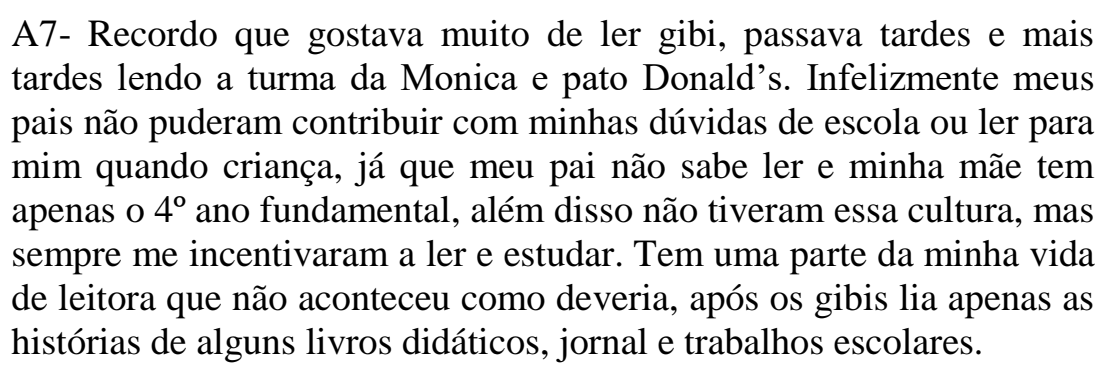

Embora a família seja elemento importante, e muitas vezes essencial, na formação do leitor, observamos que nem sempre isso é possível, pois, assim como no caso de A7, há muitos pais que não tiveram o privilégio de poder representar-se como modelo de leitor ideal para os filhos. No entanto, A7 destaca um fato interessante em

\footnotetext{
${ }^{7}$ Aqui parece vir à cena a biblioteca como o lugar da falta ou do excesso, conforme nos apresenta Barthes (1984)

${ }^{8}$ A noção de comunidade de leitores, formulada por Charthier (1999a) nos ajuda a entender esse movimento (frenético, não linear) e esse movimento do leitor.
}

Volume 18

Número 39 


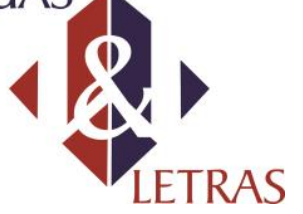

seu depoimento: apesar de seus pais não "terem essa cultura” (acesso à cultura escrita), isso não foi empecilho para que eles incentivassem os filhos a ler. Ou seja, o desenvolvimento de práticas da leitura pode estar ligado ao fato de o sujeito sempre ver alguém lendo ou lendo para ele, mas também pode estar ligada à falta, à ausência na família de alguém que leia, ou que tenha tal prática, mas incentiva a leitura. Assim ocorreu com A7: seus pais não puderam "contribuir" muito com a questão da leitura para realização de tarefas escolares, mas foi, talvez, exatamente, esse fato que fez seus pais incentivarem para que A7 tivesse a oportunidade que eles não tiveram no passado.

A7 destaca também que "houve uma parte da sua vida como leitora que não ocorreu como deveria", pois ela diz ter lido apenas histórias dos livros didáticos, jornais e trabalhos escolares, isto é, textos que circulavam no ambiente escolar. Ser leitora apenas de textos do livro didático, de jornais e revistas revela-se como uma experiência negativa para A7, talvez porque, no inteiro dos cursos de Letras, esse tipo de leitura, segundo aquilo que se tem por cânone atual, não a caracteriza como leitora.

Percebemos que as memórias dos alunos recém-ingressos no curso de Letras são permeadas por influências positivas e negativas, por escolhas e por imposições. Há momentos em que suas práticas de leituras são consideradas positivas, relacionadas ao prazer, mas, notamos, da mesma forma, que outras vezes essas práticas foram caracterizadas como chatas e maçantes.

\section{CONSIDERAÇÕES FINAIS}

A escola, enquanto lugar oficial de aprendizado e leitura, é, não poucas vezes, vista como a instituição que apresenta o modelo ideal para aprendizagem da leitura. De modo geral, para muitos dos sujeitos leitores, essa função é exercida de modo eficaz e adequado. Entretanto, como foi apresentado a partir de memórias de sujeitos leitores, nem sempre esse espaço alcança sucesso.

Analisando o discurso desses leitores, foi possível -perceber concepções de leitura, assinaladas por metáforas como viagem e interação, "ler é viajar"; "ler é interagir com o texto". Essas concepções corroboram as discussões empreendidas por Certeau (1994) e Barthes (1984), quando contemplam a leitura como prática em que o sujeito leitor necessariamente ocupa uma posição de destaque. Parece que, para além do óbvio, esses autores dizem ironicamente: quem ler é o leitor (não é o texto ou o autor) e é preciso considerar o lugar reservado a essa figura que nem sempre se deixa ver em sua 


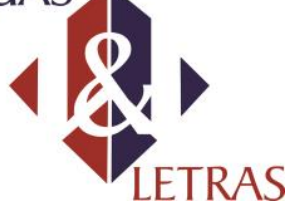

e-ISSN: 1981-4755

DOI: $10.5935 / 1981-4755.20170008$

ação de ler. Dizer isso não é efetivamente reafirmar o óbvio; implica, necessariamente, colocar-se no terreno movediço do leitor, que, ao falar sobre a sua relação com a leitura, ao trazer à memória suas histórias de leitor, sempre desafia as "certezas" que, às vezes, queremos ver registradas sobre a leitura correta, o leitor ideal, o cânone a ser lido.

Verificamos também, ao longo da análise, que os sujeitos atribuem à leitura valores, ora positivos ou negativos, quando evidenciam suas práticas ao longo do processo de escolarização da leitura, dependendo do modo como esta se lhes apresenta, baseada também nas experiências leitoras, no acesso escolarizado das leituras, no modo como o professor trabalha a leitura em sala de aula. Verificamos que a experiência escolar com a leitura oscila, no decorrer das séries (ou do tempo, conforme Abreu, 1999), ora podendo ser mais significativa (ou intensa) para o leitor, ora sinalizando um afastamento da leitura; ora assinalando momentos em que o próprio leitor, para além do que determina a escola, passa a fazer as suas escolhas. Os diferentes modos como o leitor se relaciona com a leitura necessariamente exigem uma maior reflexão sobre a formação do leitor a partir do que nos dizem os leitores - algo que foge aos limites desse artigo, daí porque remetemos o leitor para outras leituras, a exemplo de Sousa (2014 e 2010)

Por fim, gostaríamos de extrapolar a discussão até agora empreendida, sem, contudo, sair do universo de nossa proposição inicial. Para tanto, necessitamos explicitar um aspecto que até então esteve implicitamente contemplado (sempre presente) no conjunto de nossas discussões: nossos dados foram constituídos a partir de relatos de história de leitura de alunos de Letras. Não é demais repetir o óbvio: são sujeitos que estão em um curso de licenciatura (de formação de professor) que têm como função precípua formar leitores. Portanto, advogamos que as histórias de leitura de sujeitos leitores (que têm como função formar leitores) precisam ser explicitamente pensadas, discutidas, questionadas, no interior dos cursos de formação de professores. $\mathrm{O}$ formador de leitores precisa ser um leitor que tem uma (relativa) consciência sobre a sua formação como leitor, capaz de construir uma alteridade de leitor que, na distância de si e do outro, permita pensar (como profissional da educação) no leitor que deseja formar. No âmbito escolar, sempre haverá leituras impostas e aquela realizadas por prazer, revelando que, nessa instituição, o leitor caminha entre imposições e liberdades. 


\section{REFERÊNCIAS}

ABREU. Márcia. (org.) Leitura, História e História da Leitura. Campinas- SP: Mercado das Letras, 1999.

A circulação de romances como problema para a história literária. In: ESPEA 2012, evento organizado pela Escola São Paulo de Estudos Avançados em Globalização da Cultura no Século XIX, no período de 20/08/2012 a 24/08/2012. Disponível em: http://www.espea.iel.unicamp.br/index.php

BARBOSA, Socorro de Fátima P. (org). Livros e periódicos nos séulos XVIII e XIX. João Pessoa: Editora da UFPB, 2014.

BARTHES, Roland. O rumor da língua. Lisboa, Portugal: Edições 70, 1984.

BRASIL, Orientações curriculares para o ensino médio. Linguagens, códigos e suas tecnologias / Secretaria de Educação Básica. - Brasília: Ministério da Educação, Secretaria de Educação Básica, 2006. (volume 1)

CERTEAU, Michel de. A invenção do cotidiano: artes de fazer. Petrópolis, RJ: Vozes, 1994.

CHARTIER, Roger. A história ou a leitura do tempo. 2 ed. Belo Horizonte: Autêntica, 2010.

A ordem dos livros: leitores, autores e bibliotecas na Europa entre os séculos XIV e XVIII. 2. Brasília: Editora Universidade de Brasília, 1999a.

A aventura do livro: do leitor ao navegador. São Paulo: Editora UNESP/Imprensa Oficial do Estado, 1999b.

FREITAS, Raquel M. S. Memórias de leitura de alunos do Curso de Letras: práticas e concepções. (Dissertação de Mestrado). João Pessoa, 2013.

FISCHER, Steven Roger. História da leitura. $1^{\mathrm{a}}$ ed. São Paulo: Editora UNESP, 2006.

FOUCAULT, Michel. A ordem do discurso. (1970). São Paulo: edições Loyola, 2011.

LAJOLO, Marisa. Do mundo da leitura para a leitura do mundo. São Paulo: Ática, 2006.

MANGUEL, A. A cidade das palavras: as histórias que contamos para saber quem somos. São Paulo: Companhia das Letras, 2008.

. Uma história da leitura. São Paulo: Companhia das Letras, 1997.

ORLANDI. ENI. P. Discurso e leitura. 5. ed. São Paulo, Cortez; Campinas, 1 Ed. SP: Editora da Universidade Estadual de Campinas, 1988.

PECHEUX, Michel. (1975). Semântica e discurso. Trad. Eni P. Orlandi. Et.al. 4 ed. Campinas, SP: Unicamp, 2009.

PENNAC, Daniel. Como um romance (1944). Trad. Lenny Werneck. Porto Alegre, Rio de Janeiro: Rocco, 2011.

SILVA, Ezequiel Teodoro. Leitura e realidade brasileira. Porto Alegra: Mercado aberto, 1983.

SOARES, Magda. Letramento: um tema em três gêneros / Magda Soares. - 3. ed. -Belo Horizonte: Autêntica Editora, 2009

SOUSA, M. E. V. . Discursos sobre a leitura e o leitor: a contradição que ensina. Revista Letras (Curitiba) , v. 1, p. 81-98, 2014.

- Pesquisa em Língua portuguesa: da construção do objeto de pesquisa à perspectiva analítica. João Pessoa: Editora da UFPB, 2011.

. O professor e sua concepção de aluno-leitor do texto Literário. Anais do

Encontro da ALED. Recife: UFPE, 2010.

Desnaturalizando o discurso sobre a leitura. João Pessoa. Anais do VI

Congresso Internacional da ABRALIN. João Pessoa: Idéia, 2009. v. 1. 
Data de recebimento: $23 / 11 / 2016$ Data de aprovação: 10/05/2017 